\title{
Evaluation of the Electrically-Evoked Stapedial Reflex Threshold in Pediatric Cochlear Implant Users with High-Frequency Probe Tones
}

\author{
Saravanan Palani ${ }^{1}$ Arun Alexander ${ }^{10}$ Anuprasad Sreenivasan ${ }^{10}$ \\ ${ }^{1}$ Department of ENT, Jawaharlal Institute of Postgraduate Medical \\ Education and Research (JIPMER), Puducherry, India \\ Address for correspondence Saravanan Palani, MSc, Department of \\ ENT, Jawaharlal Institute of Postgraduate Medical Education and \\ Research (JIPMER), Dhanvantri Nagar, Puducherry - 605006, India \\ Int Arch Otorhinolaryngol 2022;26(4):e566-e573. \\ (e-mail: saravananpaud@gmail.com).
}

\begin{abstract}
Introduction Measurement of the electrically-evoked stapedial reflex threshold (ESRT) is an objective tool used to set the comfort levels in pediatric cochlear implant (PCI) users. The levels of ESRT have a strong correlation with comfort levels. However, the clinical utility of ESRT is limited because the ESRT response is not observed in all cochlear implant users.

Objective To assess the effects of probe-tone frequency on ESRT and its relationship with the behavioral comfort levels in $\mathrm{PCl}$ users.

Methods A total of $14 \mathrm{PCl}$ users aged between 5 and 8 years participated in the study. The ESRT levels were measured using high-frequency probe tones $(678 \mathrm{~Hz}$ and $1,000 \mathrm{~Hz}$ ), and the default $226 \mathrm{~Hz}$ probe tone. The ESRT was measured with singleelectrode stimulation across the three electrode locations (basal [E01]; middle [E11]; and apical [E22]). The ESRT levels measured with different probe tone frequencies were compared with the behavioral comfort levels.

Results The mean ESRT levels using $1,000 \mathrm{~Hz}$ and $678 \mathrm{~Hz}$ were lower than those measured using $226 \mathrm{~Hz}$, but there was no main effect of probe-tone frequency

\section{Keywords}

- cochlear implant

- electrical stapedius reflex threshold

- comfort levels

- probe tone $(p>0.05)$. A significantly high incidence of successful ESRT measurements occurred with higher-frequency probe tone $(p<0.039)$. Additionally, ESRT using higher probe tones significantly correlated with comfort levels.

Conclusion The ESRT with higher probe tones was correlated with behavioral comfort levels and increased the success rate of the measurements. Higher-frequency probe tones may be useful whenever ESRT with $226 \mathrm{~Hz}$ is not measurable.
\end{abstract}

\section{Introduction}

Programming/mapping cochlear implants plays a significant role in determining the outcomes of the patients who will use them. Mapping involves setting the lower stimulation levels/threshold levels (the minimal amount of electrical

received

December 9, 2020

accepted after revision

October 17, 2021

published online

February 8, 2022
DOI https://doi.org/ 10.1055/s-0042-1742332. ISSN 1809-9777. stimulation required for the auditory system to perceive sound) and upper stimulation levels/comfort levels (the upper limit of electrical stimulation deemed to be the most comfortable, or loud but comfortable) across the electrode array. There is a range of objective measures from which to choose when mapping the implants of pediatric

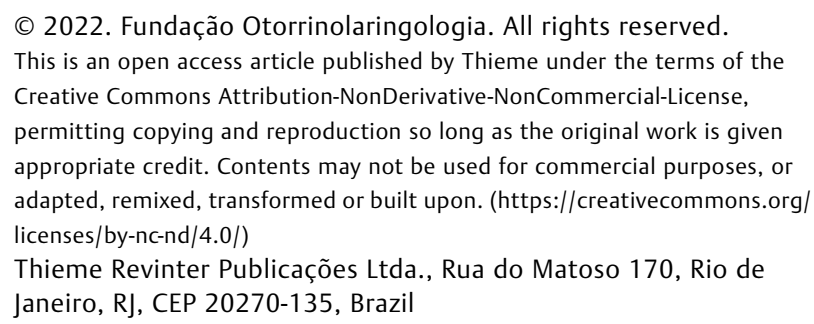

(c) 2022. Fundação Otorrinolaringologia. All rights reserved. This is an open access article published by Thieme under the terms of the Creative Commons Attribution-NonDerivative-NonCommercial-License, permitting copying and reproduction so long as the original work is given appropriate credit. Contents may not be used for commercial purposes, or adapted, remixed, transformed or built upon. (https://creativecommons.org/ licenses/by-nc-nd/4.0/) Thieme Revinter Publicações Ltda., Rua do Matoso 170, Rio de Janeiro, RJ, CEP 20270-135, Brazil 
cochlear implant (PCI) users, since reliable behavioral responses are challenging to obtain. One of them is the measurement of the electrically-evoked stapedius reflex threshold (ESRT), which is defined as the lowest level of electrical stimulation that elicits a contraction of the stapedius muscle. Numerous studies ${ }^{1-6}$ have shown a strong correlation between postoperative ESRT and the comfort levels of patients. However, the clinical usefulness of ESRT is limited because responses to it are not observed in all the cochlear implant (CI) users. A survey ${ }^{7}$ involving 47 cochlear implant centers worldwide revealed that only $14 \%$ of used ESRT measurements while setting the comfort levels. The successful measurement of the ESRT with the default probetone frequency of $226 \mathrm{~Hz}$ varied from $63 \%$ to $80 \%{ }^{1-3,5,8}$ These measurements can be affected by any insignificant alteration in the functioning of the middle ear. ${ }^{9}$ Several conditions could increase the middle ear's stiffness, such as $\mathrm{CI}$ surgery in the implanted ear and previous history of middle ear disorders in the non-implanted ear. ${ }^{10}$ Recent studies have reported that the use of higher-frequency probe tones yielded better ESRT responses. Wolfe et al. ${ }^{11}$ reported that the use of higher-frequency probe tones (of $678 \mathrm{~Hz}$ or $1,000 \mathrm{~Hz}$ ) resulted in lower ESRT levels than those obtained with $226 \mathrm{~Hz}$ in adult $\mathrm{CI}$ users. In a similar study in PCI users, Carranco Hernandez et al. ${ }^{12}$ reported that a higher probe tone could increase the successful measurement of the ESRT, especially in ipsilateral ears.

The middle ear maturational aspects affect the ESRT measurements in PCI users because a developmental trend in middle ear transmission is observed between 5 to 9 years of age. ${ }^{13}$ In ESRT measurements, it is essential to understand the use of different probe-tone frequencies and their relationship with comfort levels in younger children. There is a dearth of studies on the effectiveness of higher-frequency probe tones in ESRT measurements in the literature, especially in younger children. In addition to that, there is a need to identify the most appropriate probe-tone frequency for ESRT measurements in PCI users.

Hence, the objectives of the present study were to assess the effect of probe-tone frequencies on ESRT measurements and their relationship with behavioral comfort levels in PCI users.

\section{Methods}

The present prospective cross-sectional study was conducted in a tertiary care hospital from January 2019 to March 2020, and the participants were recruited from the Cochlear Implant Clinic at the Department of Ear, Nose and Throat (ENT). The study received approval from the institutional Ethics Committee for Human Studies (JIP/IEC/2018/46). The sample was composed of $14 \mathrm{PCI}$ users (Nucleus CI24RE with full-band straight electrode, Cochlear, New South Wales, Australia). Only 1 out of the 14 participants was a bilateral $\mathrm{CI}$ user, and the remaining 13 were unilateral $\mathrm{CI}$ users. The mean age of the sample was 6.14 years (range: 5 to 8 years; standard deviation $[\mathrm{SD}]=1.02 ; 10$ males and 4 females). All the participants were diagnosed with bilateral severe to profound hearing
Table 1 Demographics of the study sample

\begin{tabular}{|l|l|l|l|l|l|}
\hline $\begin{array}{l}\text { Partici- } \\
\text { pant }\end{array}$ & $\begin{array}{l}\text { Age } \\
\text { (years) }\end{array}$ & $\begin{array}{l}\text { Age at } \\
\text { implantation }\end{array}$ & $\begin{array}{l}\text { Experience } \\
\text { with the } \\
\text { cochlear } \\
\text { implant } \\
\text { (years) }\end{array}$ & $\begin{array}{l}\text { Unilateral/ } \\
\text { Bilateral }\end{array}$ & Implant \\
\hline P01 & 7 & 4 & 3 & Bilateral & CI24RE(ST) \\
\hline P02 & 7 & 4 & 3 & Unilateral & CI24RE(ST) \\
\hline P03 & 7 & 5 & 2 & Unilateral & CI24RE(ST) \\
\hline P04 & 5 & 3 & 2 & Unilateral & CI24RE(ST) \\
\hline P05 & 5 & 2 & 3 & Unilateral & CI24RE(ST) \\
\hline P06 & 6 & 3 & 3 & Unilateral & CI24RE(ST) \\
\hline P07 & 8 & 4 & 4 & Unilateral & CI24RE(ST) \\
\hline P08 & 5 & 3 & 2 & Unilateral & CI24RE(ST) \\
\hline P09 & 7 & 4 & 2 & Unilateral & CI24RE(ST) \\
\hline P10 & 6 & 2 & 4 & Unilateral & CI24RE(ST) \\
\hline P11 & 7 & 2 & 5 & Unilateral & CI24RE(ST) \\
\hline P12 & 5 & 3 & 2 & Unilateral & CI24RE(ST) \\
\hline P13 & 6 & 4 & 2 & Unilateral & CI24RE(ST) \\
\hline P14 & 5 & 2 & 3 & Unilateral & CI24RE(ST) \\
\hline Mean & 6.14 & 3.21 & 2.85 & NA & NA \\
(SD) & $(1.02)$ & $(0.97)$ & $(0.94)$ & & \\
\hline
\end{tabular}

Abbreviations: NA, not applicable; SD, standard, deviation; ST, straight array.

loss. - Table 1 shows the demographics of the participants and their experience with the $\mathrm{CI}$ device.

All of the test procedures were performed in a soundtreated room with appropriate acoustic isolation and noise within the maximum permissible levels. The present study involved the following tests.

\section{ESRT Measurements}

Before the ESRT measurements, all of the participants underwent an otoscopic examination and tympanometry to rule out possible middle-ear dysfunction. The Tympstar Pro (Grason-Stadler Industries [GSI], Eden Prairie, MN, Unites States) immittance audiometer was used to perform the tympanometry and measure the ESRT, whose levels were estimated in unilaterally-implanted participants by placing the probe in the contralateral non-implanted ear. In the case of the bilateral CI user, the ESRT levels were estimated by placing the probe in the ear contralateral to the ear stimulated. All of the participants had type-A tympanograms in the probe ear, that is, the static compliance fell between $0.3 \mathrm{~mL}$ and $1.75 \mathrm{~mL}$, and the peak pressure ranged from -100 to +60 daPa. - Table 2 shows the tympanometric results of the participants.

The procedure for ESRT measurements was as follows: In the immittance meter, reflex decay mode with a recording duration of 60 seconds was selected. The stimulus levels were set at a minimum ( $35 \mathrm{dBHL})$ and enabled the contralateral reflex measurement. The probe-tone frequency was set at $226 \mathrm{~Hz}, 678 \mathrm{~Hz}$, or $1,000 \mathrm{~Hz}$, and the ESRT levels were estimated for all 3 probe tones. 
Table 2 Tympanometric results of the test ear

\begin{tabular}{|l|l|l|l|l|}
\hline Participant & Ear & $\begin{array}{l}\text { Ya } \\
\text { (mmho) }\end{array}$ & $\begin{array}{l}\text { Pressure } \\
\text { (daPa) }\end{array}$ & $\begin{array}{l}\text { ECV } \\
\text { (mmho) }\end{array}$ \\
\hline P01 & Right & 0.32 & -33 & 1.1 \\
\hline P01 & Left & 0.42 & -21 & 0.9 \\
\hline P02 & Right & 0.63 & -7 & 0.8 \\
\hline P03 & Right & 0.71 & -37 & 1.2 \\
\hline P04 & Right & 0.49 & -35 & 1.3 \\
\hline P05 & Left & 0.52 & -4 & 1.1 \\
\hline P06 & Right & 0.84 & -77 & 0.8 \\
\hline P07 & Right & 1.11 & -16 & 1.5 \\
\hline P08 & Left & 0.36 & -39 & 0.8 \\
\hline P09 & Right & 0.32 & -35 & 0.8 \\
\hline P10 & Left & 0.9 & -15 & 1.1 \\
\hline P11 & Right & 0.88 & -21 & 1.1 \\
\hline P12 & Right & 0.41 & -44 & 0.9 \\
\hline P13 & Right & 0.61 & -16 & 0.8 \\
\hline P14 & Right & 0.44 & -14 & 0.8 \\
\hline $\begin{array}{l}\text { Mean } \\
\text { (SD) }\end{array}$ & NA & 0.59 & -27.6 & 1.00 \\
\hline
\end{tabular}

Abbreviations: NA, not applicable; SD, standard deviation; Ya: Admittance/static compliance; ECV: ear canal volume.

The participant's speech processor (CP800 series or Freedom speech processor, Cochlear) and the Custom Sound EP (Cochlear) software, version 4.2, were used to measure the ESRT. The impedance was measured for all the electrodes before the measurement of the ESRT, and it was found to be within normal limits across all the electrodes for all the study participants. For ESRT measurements, biphasic pulse trains were presented with a duration, pulse width and stimulus rate of $500 \mathrm{msec}, 25 \mu \mathrm{s}$ and 900 pulses per second, respectively. The ESRT was measured for 3 electrodes (E01, E11, and E22) across the array, and the levels were first estimated in the apical electrode (E22), followed by a middle electrode (E11), and the basal electrode (E01). The threshold (T) level of the existing MAP used by the child at the time of testing served as the starting level for the ESRT measurements. The stimulation then increased in 5 current level (CL) steps until a time-locked visible decrease in admittance was noted. The stimulation levels increased 3 to 4 times in 2 CL steps and confirmed the growth and repeatability of the time-locked ESRT by presenting the biphasic pulse trains at each level 2 to 3 times. The presence of ESRT response was confirmed by a replicable decrease in admittance and by the growth in reflex amplitude.

Then, the bracketing method was incorporated by increasing and decreasing pulse amplitude in 2 CL steps, depending on the presence or absence of reflex. Thus, the ESRT measurement was performed using both ascending and descending runs alternatively. The ESRT threshold is defined as the lowest $\mathrm{CL}$, which produces a definite, repeatable deflection $\geq$ $0.03 \mathrm{mmho}$ that could be detected at least twice during the measurements. During the ESRT measurements, a 5-point rating scale (very soft, soft, medium, loud but okay, very loud) was used to classify the participants' loudness. The ESRT measurement terminated at the level where the ESRT response was observed or when the stimulus levels were classified as "very loud" in the loudness rating. In the present study, the stimulations levels used were well within the voltage compliance in all tested electrodes and for all the participants.

\section{Measurement of Behavioral Comfort Level}

The measurement of behavioral comfort levels was performed independently, using an ascending approach, after the completion of the ESRT testing. Stimulation started at the T level of the participant's existing MAP at the time of testing. The same scale was used to classify the loudness. During the measurement, a loudness chart with pictorial representations of loudness levels was used. The stimulation levels increased in $5 \mathrm{CL}$ until the child indicated "medium" on the scale; then, they increased in 2 CL steps until the child indicated "loud but okay." Along with the loudness scale, the child's physiological state was monitored during or a short period after the stimulus presentation by observing their auditory behavior, like changes in facial expression or level of activity. The behavioral comfort level (estimated individually in 3 electrodes: E01, E11, and E22) is considered the maximum current level, which is classified as "loud but okay."

The statistical analysis was performed using the Statistical Package for the Social Sciences (IBM SPSS Statistics for Windows, IBM Corp., Armonk, NY, United States), version 19.0. The one-sample Kolmogorov-Smirnov test revealed that all the data ( - Appendix A) followed a normal distribution $(p>0.05)$. The ESRT levels measured using 3 different probe-tone frequencies $(226 \mathrm{~Hz}, 678 \mathrm{~Hz}$, and $1,000 \mathrm{~Hz}$ ) across 3 electrode locations (apical, middle, and basal) were analyzed using two-factor repeated measures analysis of variance (ANOVA). The independent variables for the analysis were probe-tone frequencies and electrode locations. To measure the incidence of successful ESRT measurement as a function of probe-tone frequencies, the Cochran Q test, was performed. A correlational analysis (Pearson correlation) was performed to measure the relationship between ESRT measurements across different probe-tone frequencies and comfort levels for each electrode location. Values of $p<0.05$ were considered statistically significant.

\section{Results}

The average ESRT measurements with the probe-tone frequencies of $1,000 \mathrm{~Hz}$ and $678 \mathrm{~Hz}$ were lower than those measured using $226 \mathrm{~Hz}$. - Fig. 1 shows the average ESRT values across different probe-tone frequencies and electrode locations.

The statistical analysis using two-factor repeated measures ANOVA revealed no main effect of probe-tone frequencies $\left.\left(\mathrm{F}[2,20]=1.24 ; p>0.05 ; \eta p^{2}=0.11\right]\right)$ on the ESRT levels; however, there was a significant main effect of the 


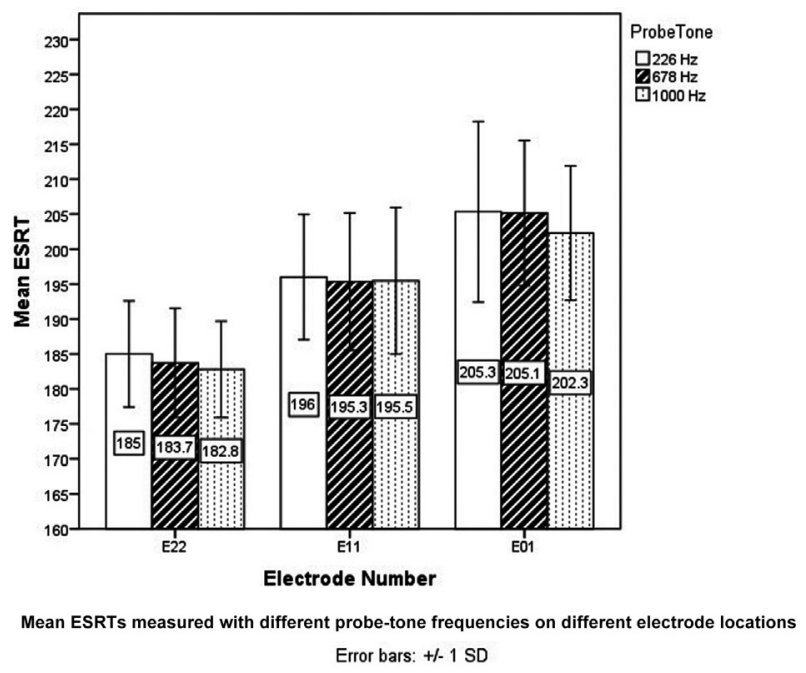

Fig. 1 Mean ESRTs measured with different probe-tone frequencies on different electrode locations. The error bars indicate $+\mid-1$ standard deviation (SD) from the mean.

electrode locations $\left.\left(\mathrm{F}[2,20]=18.7 ; p<0.0001 ; \eta p^{2}=0.65\right]\right)$. The mean ESRT levels on the apical electrode were significantly lower, by $11.8 \mathrm{CL}$, compared with the middle electrode, and lower by $22.2 \mathrm{CL}$ than the levels measured on basal electrode. When comparing the levels measured on the middle and basal electrodes the mean levels on the middle electrode were significantly lower, by $10.3 \mathrm{CL}$. There was no interaction effect observed between probe-tone frequency and electrode location $\left.\left(\mathrm{F}[4,40]=0.84 ; p>0.05 ; \eta p^{2}=0.07\right]\right)$. Regarding the electrode locations, the mean behavioral comfort levels were lowest for the apical electrode (E22), followed by the middle electrode (E11), and the highest levels were observed in the basal electrode (E01). - Fig. 2 shows the average comfort levels across different electrode locations.

The results of the measurements showed that, for the 226$\mathrm{Hz}$ probe-tone frequency, the ESRT was measurable in 12/15

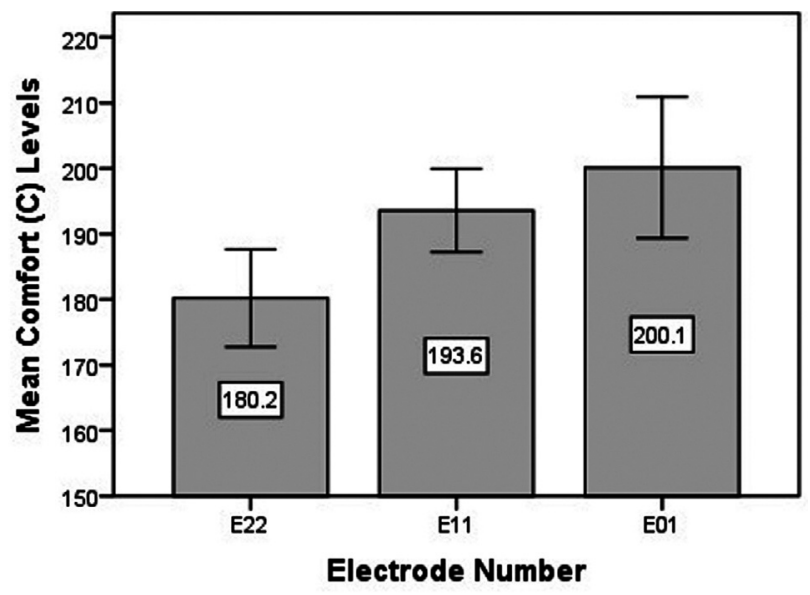

Error bars: $+/-1 \mathrm{SD}$

Fig. 2 Mean behavioral comfort (C) levels for different electrode locations. The error bars indicate $+/-1$ standard deviation (SD) from the mean. ears ( $80 \%), 14 / 15$ ears (93.33\%), and $14 / 15$ ears $(93.33 \%)$ on the basal, middle, and apical electrodes respectively; for $678 \mathrm{~Hz}, 12 / 15$ ears (80\%), $15 / 15$ ears (100\%), and $14 / 15$ (93.33\%) had successful ESRT measurements on the basal, middle, and apical electrode respectively; and, for $1,000 \mathrm{~Hz}$, $14 / 15$ ears (93.33\%) on the basal electrode, and 15/15 ears $(100 \%)$ on both the middle and apical electrode.

Overall, out of 45 electrodes tested, measurable responses were found in 40/45 (88.8\%), 43/45 (95.5\%), and 44/45 (97.7\%) electrodes using the probe-tone frequencies of $226 \mathrm{~Hz}, 678 \mathrm{~Hz}$, and $1,000 \mathrm{~Hz}$ respectively. A total of 3 participants (P04, P06, and P10) showed no measurable ESRT at $226 \mathrm{~Hz}$, but had measurable ESRTs with $678 \mathrm{~Hz}$ or $1,000 \mathrm{~Hz}$. The Cochran $Q$ test was used to determine the incidence of successful ESRT measurements (present or absent) as a function of probe-tone frequencies, and it revealed a significant difference in the incidence of successful ESRT measurements as a function of 3 probe-tone frequencies $(\mathrm{Q}[2]=6.5$; $p=0.039$ ). The highest pair-wise difference was between $226 \mathrm{~Hz}$ and $1,000 \mathrm{~Hz}(p=0.046)$.

The correlation analysis ( - Table 3 ) revealed a high positive correlation between ESRT measurements using different probe-tone frequencies for all electrode locations tested. A significant relationship between ESRT values was observed using different probe-tone frequencies and comfort levels across different electrode locations. The correlation coefficient for the electrode locations ranged from 0.66 to 0.86 , 0.54 to 0.96 , and 0.61 to 0.84 for the frequencies of $226 \mathrm{~Hz}$, $678 \mathrm{~Hz}$, and $1,000 \mathrm{~Hz}$ respectively. The linear-regression analysis revealed that the measurements with the frequencies of $226 \mathrm{~Hz}, 678 \mathrm{~Hz}$ and $1,000 \mathrm{~Hz}$ on different electrode locations can be used to reliably predict the behavioral comfort levels $(p<0.01)$. - Fig. 3 shows the scatter plot for the measurements with different frequencies versus the behavioral comfort levels.

\section{Discussion}

\section{Effect of Probe-Tone Frequency on ESRT Measurements}

The main objective of the present study was to assess the effect of three different probe-tone frequencies on ESRT measurements and their relationshipwith the behavioral comfort levels in PCI users.

In the present study, there was no significant difference in ESRT measurements for different probe-tone frequencies across all tested electrodes. This may be due to the relatively small sample size compared with that of other studies. ${ }^{11,12}$ Wolfe et al. ${ }^{11}$ measured the ESRT with $226 \mathrm{~Hz}, 678 \mathrm{~Hz}$, and $1,000 \mathrm{~Hz}$ in 23 adults using Advanced Bionics (Stäfa, Switzerland) implants. The authors ${ }^{11}$ reported that the use of higher probe-tone frequencies (of $678 \mathrm{~Hz}$ or $1,000 \mathrm{~Hz}$ ) resulted in ESRT levels that were 11 to 12.5 clinical units lower when compared with the default frequency of $226 \mathrm{~Hz}$. All of the 23 participants in this study ${ }^{11}$ had measurable ESRTs with higher probe tone frequencies, whereas, at $226 \mathrm{~Hz}, 17$ out of 23 (73.9\%) participants had measurable ESRTs. Similarly, Carranco Hernandez et al. ${ }^{12}$ evaluated the 
Table 3 Correlation analysis (Pearson correlation) between ESRT and comfort levels on different electrode locations

\begin{tabular}{|c|c|c|c|c|c|c|}
\hline \multirow[t]{3}{*}{ Objective measure } & \multicolumn{6}{|c|}{ Comfort levels } \\
\hline & \multicolumn{2}{|l|}{ E22 } & \multicolumn{2}{|l|}{ E11 } & \multicolumn{2}{|l|}{ E01 } \\
\hline & $r$ & $p$ & $r$ & $p$ & $r$ & $p$ \\
\hline ESRT $(226 \mathrm{~Hz})$ & $0.869^{*}$ & $<0.001$ & $0.666^{*}$ & $<0.01$ & $0.790^{*}$ & $<0.01$ \\
\hline ESRT $(678 \mathrm{~Hz})$ & $0.960^{*}$ & $<0.001$ & $0.544^{*}$ & $<0.05$ & $0.746^{*}$ & $<0.01$ \\
\hline ESRT $(1000 \mathrm{~Hz})$ & $0.842^{*}$ & $<0.001$ & $0.613^{*}$ & $<0.05$ & $0.781^{*}$ & $<0.01$ \\
\hline
\end{tabular}

Abbreviations: ESRT, electrically-evoked stapedius reflex threshold.

Note: ${ }^{*}$ Significant $(p<0.05)$ in the Pearson correlation.
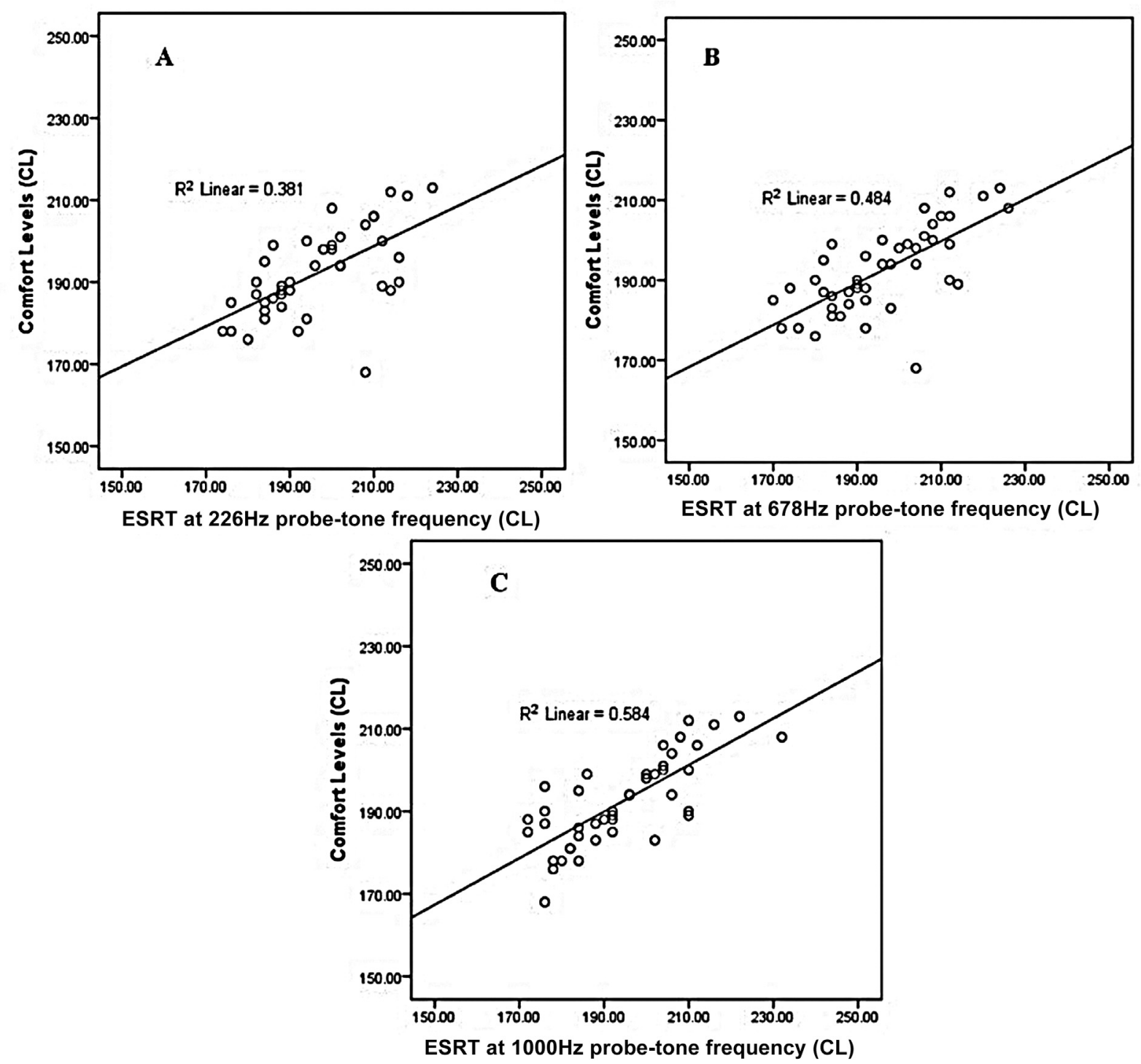

Fig. 3 Scatter plots of behavioral comfort levels versus ESRT levels. (A) ESRT (226 Hz) versuscomfort levels; (B) ESRT (678 Hz) versus comfort levels; and (C) ESRT $(1,000 \mathrm{~Hz})$ versus comfort levels.

effect of probe-tone frequency on ESRT measurements in ipsilateral and contralateral ears of 19 pediatric users of the Advanced Bionics HiRes $90 \mathrm{~K} \mathrm{Cl}$. The ipsilateral ESRT was measured in 3 (16\%), 4 (21\%), and 7 (37\%) ears, and the contralateral ESRT, in 11 (58\%), 13 (68\%), and 13 (68\%) ears for $226 \mathrm{~Hz}, 678 \mathrm{~Hz}$, and $1,000 \mathrm{~Hz}$ respectively. There was no significant difference in mean ESRT levels as a function of probe-tone frequency and ipsilateral or contralateral measurements.

In the present study, there was a higher success rate of ESRT measurements and lower thresholds with higher-frequency probe tones. During ESRT measurements, reflex- 
induced changes were predominantly observed across 500 $\mathrm{Hz}$ to $2000 \mathrm{~Hz}$ frequency region ${ }^{14}$, and hence high success rate of ESRT measures was observed with high-frequency probe tones. ${ }^{14}$ Similarly, another study reported that the reflex induced changes in admittances were more significant for the $1000 \mathrm{~Hz}$ than $250 \mathrm{~Hz}$, and the lower reflex thresholds with $1000 \mathrm{~Hz}$ than measured with $226 \mathrm{~Hz}$ probe tone. ${ }^{15}$

The use of higher-frequency probe tones increases the success rate of ESRT measurements. In the study by Carranco Hernandez et al., ${ }^{12}$ the success rates of ESRT measurements in children were of $58 \%, 68 \%, 68 \%$ for $226 \mathrm{~Hz}, 678 \mathrm{~Hz}$, and $1,000 \mathrm{~Hz}$ respectively, when measured in contralateral nonimplanted ears. In adult participants, Wolfe et al. ${ }^{11}$ reported that 13 out of 13 showed measurable ESRTs with $678 \mathrm{~Hz}$ or $1,000 \mathrm{~Hz}$, and 12 out of $13(92.3 \%)$, with $226 \mathrm{~Hz}$. The incidence of successful ESRT measurements in the present study was slightly higher than that of other studies., ${ }^{3,12,16}$ The higher incidence of the measurable ESRTs in the present study could be because all the participants had normal tympanogram findings and individual electrode stimulation during ESRT measurements in the present study. The individual electrode stimulation enabled the presentation of higher CLs before reaching an uncomfortable level for the participants. The findings of the present study are in line with those of other studies $^{12}$ that used higher-frequency probe tones to measure the ESRT. There is a significantly higher success rate of ESRT measurements using higher-frequency probe tones than the $226 \mathrm{~Hz}$ probe tone. In other words, the success rate of the measurements was higher for $1,000 \mathrm{~Hz}$ compared with $226 \mathrm{~Hz}$, maybe because the frequency of $1,000 \mathrm{~Hz}$ is closer to the resonance frequency of the middle ear. ${ }^{15,17}$ The resonance frequency of the middle ear in children aged between 6 amd 15 years ranges from $650 \mathrm{~Hz}$ to $1,400 \mathrm{~Hz}$, with a mean resonance frequency of $1,000 \mathrm{~Hz} .{ }^{18}$ However, further studies are needed to provide evidence for these statements.

\section{Relationship between ESRT and Comfort Levels}

The correlation analysis revealed a significantly high correlation $\left(R^{2}=0.69\right.$ to 0.94$)$ between ESRT levels measured with different probe-tone frequencies and behavioral comfort levels across all tested electrodes. The correlation coefficient ranged from 0.61 to 0.96 . The linear-regression analysis revealed that behavioral comfort levels can be reliably predicted with the ESRT measurements estimated using different probe-tone frequencies. The ESRTs estimated with higher-frequency probe tones also significantly correlated with the behavioral comfort levels. Lorens et al. ${ }^{19}$ studied the relationship between ESRT and behavioral comfort levels in experienced PCI users, and reported a high correlation $\left(R^{2}=0.78\right)$. Other studies ${ }^{1,2}$ have reported that the estimation of comfort levels using the ESRT is reliable and useful in PCI users. Thus, we could state that ESRT measurements could be the most useful objective tool to establish the comfort levels in PCI users.

The present study has certain limitations. The ESRT responses were measured only on the contralateral side of the implanted ear. The probable reason for non-significant probe-tone effects on ESRT measurements is the relatively small sample size. Future studies should investigate middle- ear resonance in ESRT measurements in implanted and nonimplanted ears in a larger population.

\section{Conclusion}

The findings of the present study indicate that higher-frequency probe tones, such as $678 \mathrm{~Hz}$ or $1,000 \mathrm{~Hz}$, could increase the incidence of success in measuring the ESRT in PCI users. The ESRT with higher probe tones was correlated with behavioral comfort levels. Higher-frequency probe tones may be useful whenever ESRTs are not measurable with $226 \mathrm{~Hz}$. The strong relationship of successful ESRT measurements with comfort levels means that these measurements could be used to estimate the comfort levels, especially in the pediatric population.

\section{Conflict of Interests}

The authors have no conflict of interests to declare.

\section{References}

1 Hodges AV, Balkany TJ, Ruth RA, Lambert PR, Dolan-Ash S, Schloffman JJ. Electrical middle ear muscle reflex: use in cochlear implant programming. Otolaryngol Head Neck Surg 1997;117(3 Pt 1):255-261

2 Bresnihan M, Norman G, Scott F, Viani L. Measurement of comfort levels by means of electrical stapedial reflex in children. Arch Otolaryngol Head Neck Surg 2001;127(08):963-966

3 Gordon KA, Papsin BC, Harrison RV. Toward a battery of behavioral and objective measures to achieve optimal cochlear implant stimulation levels in children. Ear Hear 2004;25(05):447-463

4 Walkowiak A, Lorens A, Polak M, et al. Evoked stapedius reflex and compound action potential thresholds versus most comfortable loudness level: assessment of their relation for charge-based fitting strategies in implant users. ORL J Otorhinolaryngol Relat Spec 2011;73(04):189-195

5 Asal S, Sobhy OA, Nooman M. The relationship between the electrical stapedial muscle reflex threshold and electrical and behavioral measures in cochlear implant patients. Egypt J Otolaryngol 2016;32(01):49-52

6 Raghunandhan S, Ravikumar A, Kameswaran M, Mandke K, Ranjith R. A clinical study of electrophysiological correlates of behavioural comfort levels in cochlear implantees. Cochlear Implants International 2014May1;15(3):145-160

7 Vaerenberg B, Smits C, De Ceulaer G, et al. Cochlear implant programming: a global survey on the state of the art. ScientificWorldJournal 2014;2014:501738

8 Spivak LG, Chute PM. The relationship between electrical acoustic reflex thresholds and behavioral comfort levels in children and adult cochlear implant patients. Ear Hear 1994;15(02):184-192

9 Wolfe J, Schafer EC. Programming cochlear implants, second ed. Plural publishingSan Diego2015

10 Hunter L, Shahnaz N. Acoustic immittance measures: Basic and advanced practice. Plural PublishingSan Diego2014

11 Wolfe J, Gilbert M, Schafer E, et al. Optimizations for the electrically-evoked stapedial reflex threshold measurement in cochlear implant recipients. Ear Hear 2017;38(02):255-261

12 Carranco Hernandez L, Cristerna Sánchez L, Camacho Olivares M, Rodríguez C, Finley CC, Saoji AA. Effect of probe-tone frequency on Ipsilateral and contralateral electrical Stapedius reflex measurement in children with Cochlear implants. Ear Hear 2019;40(03): 732-740

13 Mishra SK, Dinger Z, Renken L. Maturation of middle ear transmission in children. Hear Res 2017;344:62-67 
572 Evaluation of the Electrically-Evoked Stapedial Palani et al.

14 Wolfe J, Gifford R, Schafer E. Measurement of the electrically evoked stapedial reflex response with wideband acoustic reflectance measurement. J Am Acad Audiol 2018;29(04):337-347

15 Feeney MP, Keefe DH, Marryott LP. Contralateral acoustic reflex thresholds for tonal activators using wideband energy reflectance and admittance. J Speech Lang Hear Res 2003;46(01):128-136

16 Scheperle RA, Hajicek JJ. Wideband acoustic immittance in cochlear implant recipients: Reflectance and stapedial reflexes. Ear Hear 2020;41(04):883-895
17 Bennett MJ, Weatherby LA. Multiple probe frequency acoustic reflex measurements. Scand Audiol 1979;8(04):233-239

18 Hanks WD, Rose KJ. Middle ear resonance and acoustic immittance measures in children. J Speech Hear Res 1993;36(01): 218-222

19 Lorens A, Walkowiak A, Piotrowska A, Skarzynski H, Anderson I. ESRT and MCL correlations in experienced paediatric cochlear implant users. Cochlear Implants Int 2004;5(01):28-37 
Evaluation of the Electrically-Evoked Stapedial Palani et al. 573

Appendix A Electrically-evoked stapedius reflex threshold (ESRT)

\begin{tabular}{|c|c|c|c|c|c|c|c|c|c|c|c|c|}
\hline \multirow[t]{3}{*}{ Participant } & \multicolumn{9}{|c|}{ ESRT levels (current levels) } & \multirow{2}{*}{\multicolumn{3}{|c|}{$\begin{array}{l}\text { Comfort levels (cur- } \\
\text { rent levels) }\end{array}$}} \\
\hline & \multicolumn{3}{|c|}{$226 \mathrm{~Hz}$} & \multicolumn{3}{|c|}{$678 \mathrm{~Hz}$} & \multicolumn{3}{|c|}{$1,000 \mathrm{~Hz}$} & & & \\
\hline & $\mathrm{E} 22$ & E11 & E1 & E22 & E11 & E1 & E22 & E11 & E1 & E22 & E11 & E1 \\
\hline P01 & 184 & 188 & 188 & 184 & 188 & 190 & 188 & 188 & 190 & 183 & 187 & 188 \\
\hline P01 & 184 & 188 & 180 & 186 & 188 & 180 & 182 & 184 & 178 & 183 & 184 & 176 \\
\hline P02 & 174 & 202 & 224 & 176 & 206 & 202 & 180 & 204 & 200 & 172 & 200 & 213 \\
\hline P03 & 192 & 212 & 216 & 192 & 210 & 212 & 184 & 210 & 210 & 185 & 199 & 190 \\
\hline P04 & NR & 198 & NR & NR & 192 & 212 & 176 & 190 & 200 & 168 & 196 & 199 \\
\hline P05 & 186 & 190 & 196 & 184 & 192 & 196 & 184 & 192 & 196 & 182 & 188 & 194 \\
\hline P06 & 194 & 212 & NR & 184 & 208 & 208 & 182 & 210 & 206 & 181 & 200 & 208 \\
\hline P07 & 182 & 200 & 210 & 182 & 202 & 212 & 176 & 202 & 204 & 180 & 199 & 206 \\
\hline P08 & 202 & 202 & NR & 198 & 202 & NR & 196 & 200 & NR & 194 & 194 & 189 \\
\hline P09 & 182 & 198 & 218 & 180 & 200 & 220 & 176 & 200 & 216 & 180 & 198 & 211 \\
\hline P10 & 184 & NR & 200 & 192 & 198 & 204 & 192 & 198 & 200 & 185 & 183 & 198 \\
\hline P11 & 176 & 186 & 214 & 170 & 174 & 212 & 172 & 172 & 210 & 170 & 188 & 212 \\
\hline P12 & 184 & 186 & 208 & 182 & 184 & 208 & 184 & 186 & 206 & 180 & 199 & 204 \\
\hline P13 & 190 & 194 & 200 & 190 & 196 & 206 & 192 & 204 & 208 & 190 & 200 & 208 \\
\hline P14 & 176 & 188 & 210 & 172 & 190 & 210 & 178 & 192 & 208 & 170 & 189 & 206 \\
\hline
\end{tabular}

Abbreviation: NR, no response. 